\title{
Medical

\section{Serotypes of dengue viruses circulating in Jazan region, Saudi Arabia}

\author{
A.A. Alsheikh', O.M. Daffalla', E.M. Noureldin', W.S. Mohammed', K.J. Shrwani', \\ Y.A. Hobani', A.D. Abkar' ${ }^{2}$, F.A. Alsheikh ${ }^{3}$ and A.M. Assiri ${ }^{4}$ \\ ${ }^{1}$ National Center for Vector-Borne Diseases, MoH-Jazan, Saudi Arabia \\ ${ }^{2}$ Department of Medical Parasitology, Faculty of Medical Laboratory Sciences, University of Gezira, Sudan \\ ${ }^{3}$ Faculty of Public Health and Tropical Medicine, Jazan University, Saudi Arabia \\ ${ }^{4}$ Minister Deputy Assistant for Preventive Health, MoH-Riyadh, Saudi Arabia
}

\section{ABSTRACT}

Dengue fever is considered to be the most important mosquito-borne disease and considered as endemic disease in Jazan region, Saudi Arabia. The present study aimed to analyze the prevailing dengue virus serotypes for the first time in the region. Serum samples of 220 suspected dengue cases were collected throughout 2016 and tested by one step Reverse Transcription Polymerase Chain Reaction (RT-PCR) with a set of specific primers for detection of four dengue virus serotypes followed by sequencing the PCR products to confirm the results. Out of the 220 serum samples, 124 were found positive for dengue infection (56.4\%). Three dengue virus serotypes were detected; DEN-1, DEN-2 and DEN-3. DEN-2 is the most common and predominant type in the region rating 83.9\% (104/124), followed by DEN-1 8.9\% (11/124), and then DEN-3 7.2\% (9/124). The high seroprevalence of dengue virus infections in Jazan region indicates its endemicity. The present study highlights the importance of tracking the spread of dengue virus types and its implication for analyzing changes in dengue endemicity in specified areas over time. Complete genome sequencing is required for the three detected dengue virus serotypes circulating in the region (DEN-1, DEN-2, and DEN-3) to serve as references for any future epidemiological researches and/or outbreaks.

KEY WORDS: DENGUE FEVER, SEROTYPES, 1, 2, AND 3, JAZAN REGION, SAUDI ARABIA

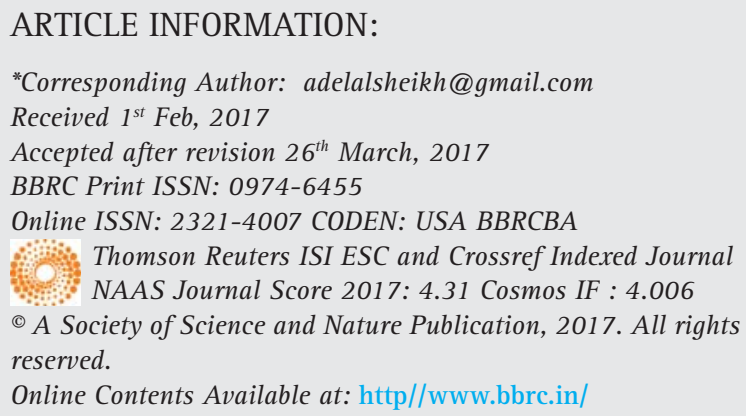




\section{INTRODUCTION}

Dengue fever is considered to be the most important re-emerging vector-borne disease worldwide and is endemic in more than 125 countries (Murray et al., 2013). Four hundred million of cases are estimated to occur annually (CDC, 2016). Dengue is a viral disease transmitted to humans by the bite of infected females of the main vector Aedes aegypti and to a lesser extent by Aedes albopictus mosquitoes (WHO, 2009).

There are five genetically related but antigenically distinct single-stranded RNA serotypes belonging to Flaviviridae family and genus Flavivirus; DEN-1, DEN2, DEN-3, DEN-4 (WHO, 1997), and DEN-5 (Mustafa et al., 2015).

However, no cross protection occurred between the dengue serotypes, the immunity is serotype specific.

According to disease severity, the World Health Organization has classified dengue into three categories; Dengue Fever (DF), Dengue Hemorrhagic Fever (DHF), and Dengue Shock Syndrome (DSS) (WHO, 1997).

Unplanned urbanization and climatic factors, including high temperatures and rainfall, might contribute to epidemics of dengue (Mackenzie et al., 2004; Crowell et al., 2011; Banu et al., 2011).Aedes mosquito is found in the urban settings, especially in tropical areas, where it maintains a sustainable relationship with humans leading to reemergence of dengue infections and creating a public health threat (Glenn and Sia, 2008).Spatial patterns in the recent and sequential circulation of DEN1-5, along with the host and virus genetics, should be regarded as potential population risk factors for sever forms of dengue fever (Guilarde et al., 2008; Chaturvedi 2006) because most secondary infection bearing heterologous dengue virus type may lead to severe disease complications (Green and Rothman, 2006; Vaughn et al., 2000; Gibbons and Vaughn, 2002; Rico-Hesse, 2003).

In Saudi Arabia, the first dengue outbreak has been reported in 1994 in Jeddah with 289 confirmed cases, and DEN-1 and DEN-2 were circulating dengue virus serotypes (Fakeeh and Zaki, 2001). Since then, several dengue fever outbreaks have been recorded in Saudi Arabia (Fakeeh and Zaki, 2003; Ahmed, 2010; Khan et al, 2008; Ayyub et al., 2006; El-Badry et al., 2013; Zaki et al., 2008) and Yemen (Madani et al., 2013). The case fatality rate was 4.6 per thousand in 2007 (Saudi Ministry of health, 2007).The incidence of dengue fever has increased in Saudi Arabia during the past few years; 6512 cases in 2013; 2081 cases in 2014; and 4312 cases in 2015 (Saudi Ministry of health, 2016).

The emergence of DEN-3 in Jeddah was in 1997 (Fakeeh and Zaki, 2001), and since then all the 3 dengue serotypes (DEN 1-3) were being circulated in the city (Azhar et al., 2015). Recently, Organji et al (2017) have reported DEN-1, DEN-2, and DEN-3 to be circulated in Makkah city. In Jazan region, there were 1790 confirmed dengue cases between 2005 and 2016 with highest outbreaks in 2016 (555 cases), followed by 2010 (290 cases), and 2012 (289 cases) (Dengue control program in Jazan). Al-Arzaqi et al (2013) reported dengue prevalence of up to $26.5 \%$ in Jazan region, while Gamil et al (2014) noted $47.74 \%$ dengue positivity rate in the area.To the best of our knowledge, no data has been published on the circulation of dengue virus serotypes in Jazan region, thus our present study is the first of its own and aimed to analyze the prevalence of dengue virus serotypes circulating in Jazan region, southwest of Saudi Arabia.

\section{MATERIAL AND METHODS}

Study area: Jazan Region in Southwest Saudi Arabia lies between $16^{\circ}-12$, and $18^{\circ}-25$, latitude north. It is bordered in the South by Arabic republic of Yemen with total area of about 22,000 $\mathrm{km}^{2}$ and 1.3 million populations (census 2011). Thirty percent of the population concentrated in six major cities, and the remainders living in over 3500 villages (Alsheikh, 2011). Jazan region is situated in the subtropical zone and has average monthly temperatures ranging between $25.8^{\circ} \mathrm{C}$ in January to $33.4^{\circ} \mathrm{C}$ in July. The average relative humidity ranges between $55 \%$ and $72.5 \%$. The rainy season is started at August through October with a monthly average of 77 and 56.7 $\mathrm{mm}$, respectively (Alsheikh, 2011). Jazan is divided into eleven small Governates (Al-Aridah, Damad, Twal, AlAhad, Jazan , Al-Khobah, Samttah, Abuareesh, Sabyah, Beash and Al-Darb), these locations (Fig.1) although with different altitudes and geographical Characteristics, they are almost share the same demographical, agricultural, educational, cultural, housing, health system, and environmental characteristics.

Sampling: During 2016 about 220 suspected dengue fever patients serum samples included in this study were collected from five different hospitals in Jazan region and stored at $-80^{\circ}$ till further use.

RNA isolation: High Pure Viral Nucleic Acid Kit from Roche applied science (Germany) used for extraction of RNA follow the manufacture procedure; $200 \mu \mathrm{l}$ of binding buffer supplemented with poly (A) and 50 $\mu$ Proteinase K added to $200 \mu$ l of serum sample then mixed immediately and incubated for 10 minutes at $72^{\circ} \mathrm{C}$. Addition of $100 \mu$ l Proteinase $\mathrm{K}$ was mixed with sample and transferred to High Filter Tube inserted into Collection Tube. After centrifugation for 1 minute at $10000 \mathrm{rpm}$, the collection tube was discarded. The filter tube combined with new collection tube and $500 \mu \mathrm{l}$ of inhibitor removal buffer was added and centrifuged for 1 minute at $10000 \mathrm{rpm}$. After changing collection 


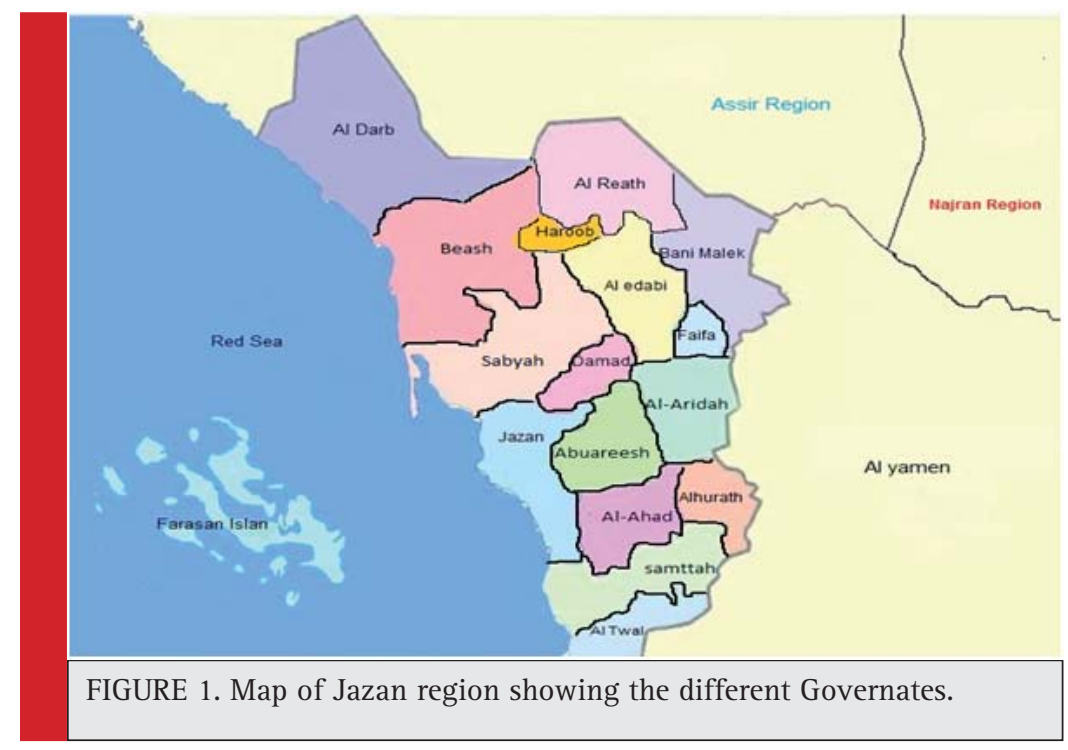

tube, the high filter tube washed twice by adding 450 $\mu l$ of wash buffer at the same condition of centrifugation, followed by centrifugation for 15 seconds at 13000 rpm to remove any residual wash buffer. Then the high filter tube was inserted into nuclease free, sterile $1.5 \mathrm{ml}$ centrifuge tube and $50 \mu \mathrm{l}$ of elution buffer was added to elute the viral nucleic acid by centrifugation at 10000 rpm for 1 minute.

\section{Reverse Transcriptase Polymerase Chain Reaction (RT-PCR)}

One step RT- PCR is a rapid, sensitive, and simple for dengue serotype-specific diagnosis method. The test was performed according to the protocol of Lanciotti et al (1992) with some modification; DEN consensus primers and serotype-specific primers (Table 1) were used to amplify the viral genome in this study and synthesized in Integrated DNA Technology (Belgium). The one step RT-PCR reactions were performed according to access RT-PCR-system protocol (Promega-USA) in total volume of $50 \mu \mathrm{l}$ containing $10 \mu \mathrm{l}$ of AMV/Tfl 5X Reaction Buffer, $1 \mu$ l of dNTP Mix (10mM each dNTP, final concentration $0.2 \mathrm{mM}$ ), $2 \mu \mathrm{l}$ of $25 \mathrm{mM} \mathrm{MgSO} 4$ (final concentration $1 \mathrm{mM}), 1 \mu \mathrm{l}$ of AMV Reverse Transcriptase $5 \mathrm{u} /$ $\mu l$ (final concentration $0.1 \mathrm{u} / \mu \mathrm{l}$ ), $1 \mu \mathrm{l}$ of Tfl DNA Polymerase $5 \mathrm{u} / \mu \mathrm{l}$ (final concentration $0.1 \mathrm{u} / \mu \mathrm{l}$ ), 50pmol (final concentration $1 \mu \mathrm{M}$ ) of each forward (D1) and reverse (D2) primers, $5 \mu$ l of RNA virus and nuclease free water to total volume $50 \mu$ l. The thermal cycling incubations temperatures programmed as follows: incubation for 1 hour at $42^{\circ} \mathrm{C}$ (to convert the RNA to cDNA) then initial denaturation for 3 minutes at $94^{\circ} \mathrm{C}$ followed by 35 cycle of denaturation $\left(94^{\circ} \mathrm{C}\right.$, for 30 second), primers annealing $\left(55^{\circ} \mathrm{C}\right.$ for 1 minute), primer extension $\left(72^{\circ} \mathrm{C}\right.$ for 2 minutes) and final extension for 5 minutes.

\section{Nested-PCR}

Nested PCR was performed in 2 tubes for each sample in $50 \mu \mathrm{l}$ reaction mixture containing $25 \mu \mathrm{l} \mathrm{GoTag}{ }^{\circledR} \mathrm{G} 2$ green master mix ready to use from Promega, $10 \mu \mathrm{l}$ of the diluted (1:100) RT-PCR product, 50 pmol (final concentration $1 \mu \mathrm{M})$ of each forward primer D1 and TS1, TS3 as reverse primers for the first tube and TS2, TS4 as reveres primers for another tube. The samples were subjected to initial denaturation at $94^{\circ} \mathrm{C}$ for 3 minutes, 30 cycles of denaturation $\left(94^{\circ} \mathrm{C}, 30 \mathrm{~s}\right)$, primer annealing $\left(55^{\circ} \mathrm{C}, 1 \mathrm{~min}\right)$, primer extension $\left(72^{\circ} \mathrm{C}, 2 \mathrm{~min}\right)$ and final extension for 5 minutes. In each run negative and positive controls were included. The PCR products of nested amplification were analyzed by gel electrophoresis (1.5 agarose in Tris-Acetate EDTA buffer) staining with ethidium promide. The visualization was carried out using Gel Doc XR Imaging System (Bio-Rad).

\section{Sequencing and bioinformatics analysis}

Purification and standard sequencing for RT- PCR products were performed by Macrogen Company (Seoul, Korea). Sequencing reactions were performed in a MJ Research PTC-225 Peltier Thermal Cycler using a ABI PRISM $^{\circledR}$ BigDyeTM Terminator Cycle Sequencing Kits with AmpliTaq ${ }^{\circledR}$ DNA polymerase (FS enzyme) (Applied Biosystems), following the protocols supplied by the manufacturer. Single-pass sequencing was performed on each template using D1 (forward) primer. The fluorescent-labeled fragments were purified from the unincorporated terminators with Big Dye ${ }^{\circledR} \mathrm{X}$ Terminator ${ }^{\mathrm{rm}}$ purification protocol. The samples were resuspended in distilled water and subjected to electrophoresis in an ABI 3730xl sequencer (Applied Biosystems). The sequences were searched for sequence similarity through BLAST 
Table 1. oligonucleotide primers used in RT-PCR and Nested-PCR

\begin{tabular}{|l|l|l|l|}
\hline primer & Sequence $5-3$ & $\begin{array}{l}\text { Genome } \\
\text { position }\end{array}$ & Size in bp \\
\hline D1 & TCAATATGCTGAAACGCGCGAGAAACCG & $134-161$ & 511 \\
\hline D2 & TTGCACCAACAGTCAATGTCTTCAGGTTC & $616-644$ & 511 \\
\hline TS1 & CGTCTCAGTGATCCGGGGG & $568-586$ & 482 (Dl and TS1) \\
\hline TS2 & CGCCACAAGGGCCATGAACAG & $232-252$ & 119 (Dl and TS2) \\
\hline TS3 & TAACATCATCATGAGACAGAGC & $400-421$ & $290(\mathrm{Dl}$ and TS3) \\
\hline TS4 & CTCTGTTGTCTTAAACAAGAGA & $506-527$ & $392(\mathrm{Dl}$ and TS4) \\
\hline
\end{tabular}

\begin{tabular}{|l|l|l|l|l|l|}
\hline \multicolumn{6}{|l|}{ Table 2. Results of dengue virus serotyping using RT-PCR and nested-PCR } \\
\hline No of samples & +ve DEN & +ve DEN-1 & +ve DEN-2 & +ve DEN-3 & +ve DEN-4 \\
\hline 220 & $124(56.4 \%)$ & $11(8.9 \%)$ & $104(83.9 \%)$ & $9(7.2 \%)$ & $0(0 \%)$ \\
\hline
\end{tabular}

(www.ncbi.nlm.nih.gov/BLAST/) (Atschul et al., 1997) and compared to reference sequences of Dengue serotypes detected in BLAST and downloaded from GenBank (www.ncbi.nlm.nih.gov/genbank/).

Similarity tree was obtained from database online by phylogeny.fr (http://www.phylogeny.fr/).

\section{RESULTS}

RT-PCR and Nested-PCR: One hundred twenty four samples out of $220(56.4 \%)$ suspected patient serum samples tested by RT-PCR were confirmed positive for dengue virus when using D1 and D2 primers (511bp) for all serotypes, and the RT-PCR product was used as a sample for the nested-PCR using a set of serotypespecific primers pair as described in the methodology.
Three dengue virus types (DEN-1, DEN-2 and DEN-3) were detected and the results showed that DEN-2 is the most common and predominant type in Jazan region rating one hundred four out of one hundred twenty four (83.9\%), followed by DEN-1 (eleven out of one hundred twenty four, 8.9\%), and then DEN-3 (nine of one hundred twenty four, 7.2\%) and serotype 4 was not detected (Table 2 and Fig. 2).

Sequencing: To confirm the serotype-specific results, the partial sequencing was done for nineteen RT-PCR product samples represent the three serotypes (DEN-1, DEN-2, and DEN-3). The Blast search showed that the sequences of our samples aligned along with many published sequences of dengue virus serotypes as shown in Table 3 and Fig.3, Fig.4 and Fig.5, and similarity tree (Fig.6, Fig.7 and Fig.8) which illustrates the Gen bank accession numbers and the country of isolates.

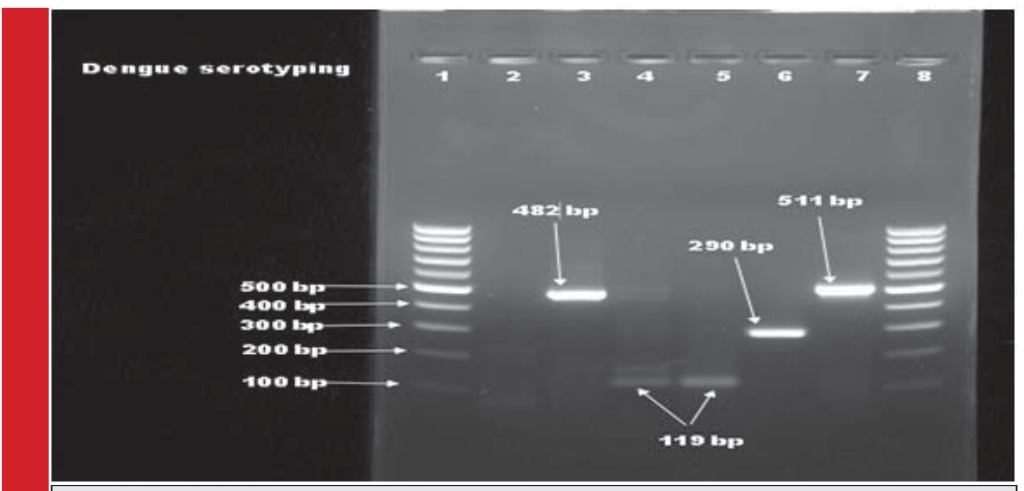

FIGURE 2. Agarose gel electrophoresis of RT-PCR (D1, D2 primers) and nested-PCR by the specific primers. Lane 1 and 8 DNA 100bp marker, lane (2) negative control, lane (3) positive sample DEN-1, lane $(4,5)$ positive samples DEN-2, lane (6) positive sample DEN-3 and lane (7) positive RT-PCR product sample (D1 and D2 primers for all serotypes). 


\begin{tabular}{|l|l|l|l|l|l|}
\hline \multicolumn{2}{|c|}{ Table 3. Results of RT-PCR and nested-PCR } \\
\hline $\begin{array}{l}\text { Gen bank } \\
\text { accession No }\end{array}$ & Country & $\begin{array}{l}\text { Gen bank } \\
\text { accession No }\end{array}$ & Country & $\begin{array}{l}\text { Gen bank } \\
\text { accession No }\end{array}$ & Country \\
\hline AB608788 & Taiwan & JN935383 & India & KM097092 & India \\
\hline KJ649286 & Saudi Arabia & KU351296 & India & KM097092 & Singapore \\
\hline JN638338 & Thailand & GU968539 & India & KF954949 & China \\
\hline AF298808 & Djibouti & KX577706 & China & GQ466079 & India \\
\hline Z74047 & Vietnam & KT180256 & India & FJ644564 & India \\
\hline AF538024 & Cambodia & KU351306 & India & DQ317393 & India \\
\hline KU509258 & Eritrea & JQ639472 & India & KU216208 & India \\
\hline
\end{tabular}

Sequencing of DEN-1 in this study revealed that it is in close similarity to some Asian (Taiwan, Saudi Arabia, Thailand, Vietnam, and Cambodia) and African (Djibouti and Eritrea) types (Table 3, Fig.3, and Fig.6). DEN-2 on other hand, is similar to varies Indian types (Table 3, Fig.4, and Fig.7), while DEN-3 is in similarity to some Asian types including India, China, and Singapore (Table 3, Fig.5, and Fig.8).

\section{DISCUSSION}

Jazan region has witnessed several outbreaks during the recent decade (290 cases in 2010, 289 cases in 2012, and 555 cases in 2016 - Dengue control program in Jazan). The current available data on dengue in Jazan has concentrated mainly on serological surveys (Al-Arzaqi et al., 2013; Gamil et al., 2014) and has not analyzed the circulating serotypes in the region.

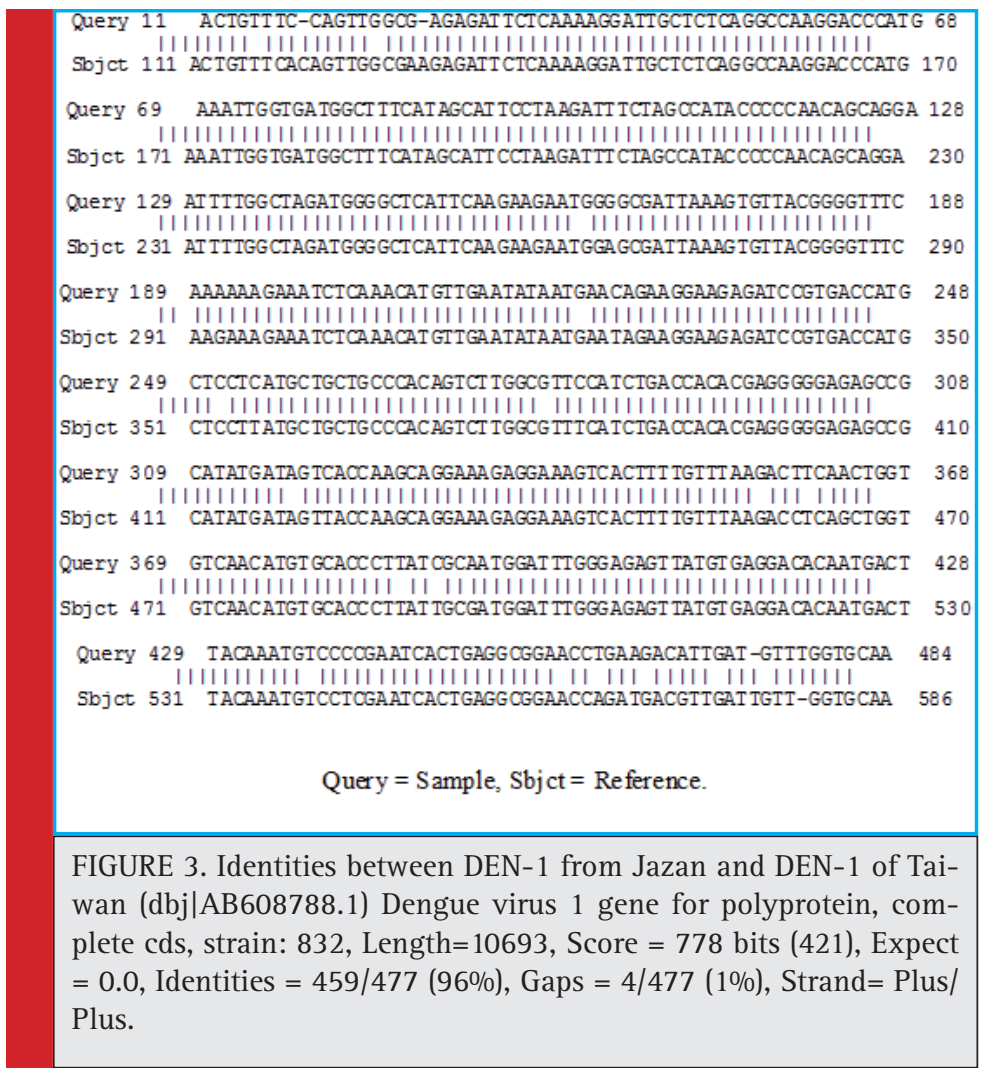




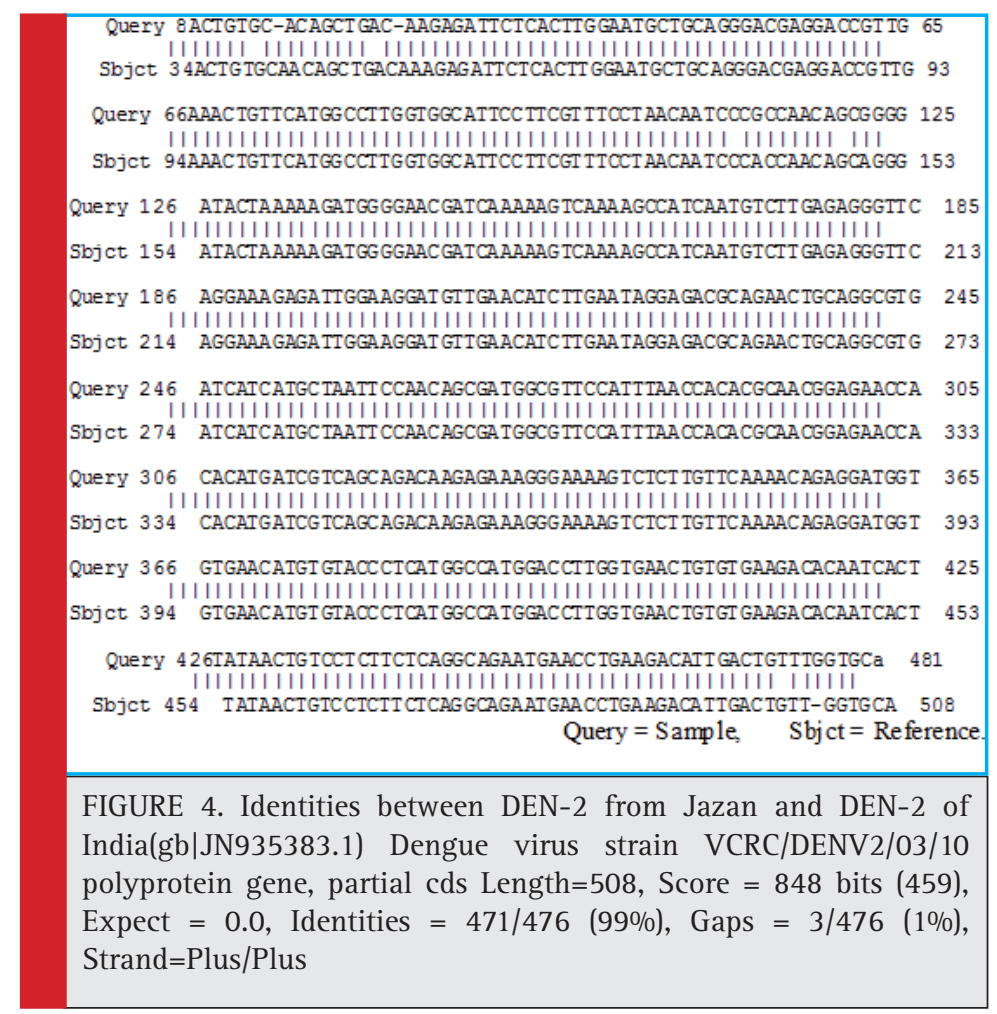

Our results indicated that dengue fever is becoming highly prevalent in Jazan region (56.4\%) compared to the previous reports of Al-Arzaqi et al (2013) and Gamil et el (2014) who reported dengue prevalence of 26.5\% and $47.74 \%$, respectively, in the region. In this study, three dengue virus types (DEN-1,DEN-2 and DEN-3) were found circulating in Jazan region with the predominance of DEN-2 scoring 104 out of 124 dengue

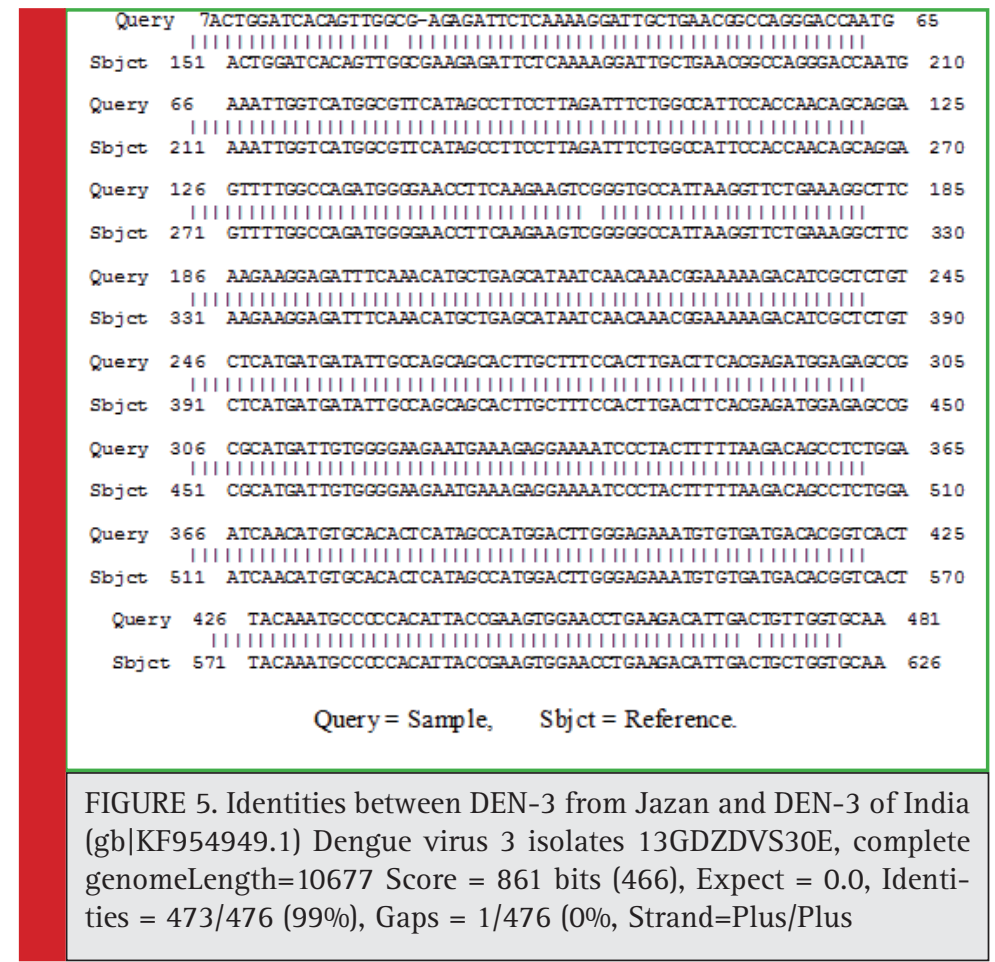




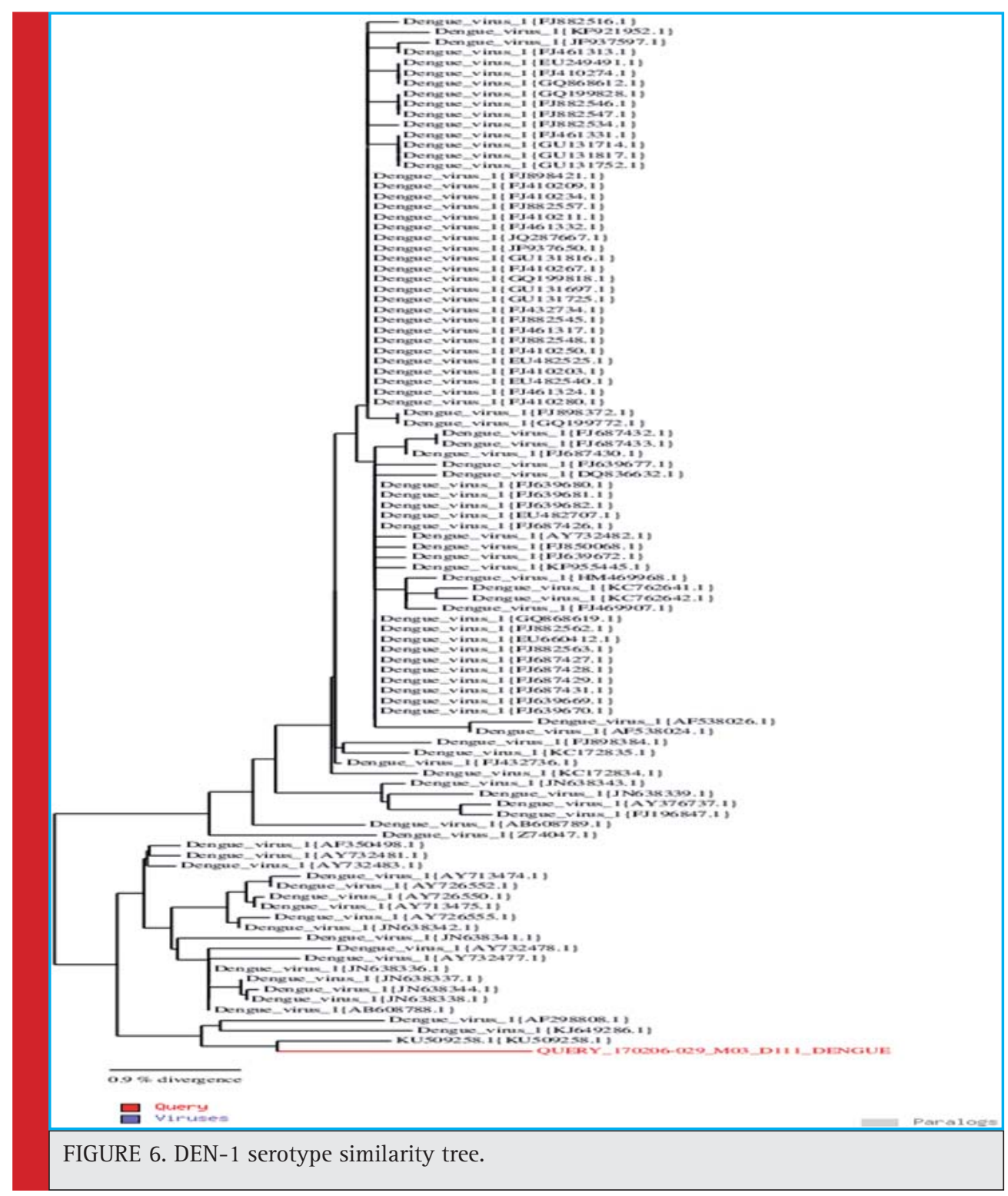

positive samples (83.9\%), followed by DEN-1 (11 out of $124-8.9 \%$ ), and then DEN-3 (9 of $124-7.2 \%$ ), however serotype 4 was not detected in any of the 124 dengue cases. This finding is in complete accordance with the work of Fakeeh and Zaki (2001) who reported that DEN-2 was the predominant serotype, followed by DEN1, and DEN-3 in Jeddah, Saudi Arabia. Whereas Organji et al (2017) in Makkah city, showed that DEN-1 was the predominant dengue virus type, followed by DEN-2 and then DEN-3, although the positive blood samples they used were only six.

The results also coincide partially with the findings of Khan et al (2008) who reported high prevalence of the DEN-2 in contrast to the prevalence of DEN-1 found by Organji et al (2017) in Makkah city.In Jeddah, Zaki et al
(2008) revealed that DEN-1 and DEN-2 caused the major outbreak in 1994, while DEN-3 emerged in 1997. Moreover, they indicated two genotypes for DEN-1 (AmericaAfrica genotype, and Asia-2 genotype), DEN-2 genotype clustered within Cosmopolitan genotype, and DEN-3 clustered within genotype III.

In the present study, we found DEN-2 to be the predominant dengue virus type, a result which is in line with the reports of Fakeeh and Zaki $(2001,2003)$ and Zaki et al. (2008) who stated that DENV-2 virus is the predominant serotype in Saudi Arabia particularly in western Saudi Arabia since 1992.El-Kafrawy et al. (2016) showed that DEN-2 isolate from Jeddah belongs to the Cosmopolitan genotype was most genetically related to isolates from Pakistan circulating from 2008 to 2013.The 


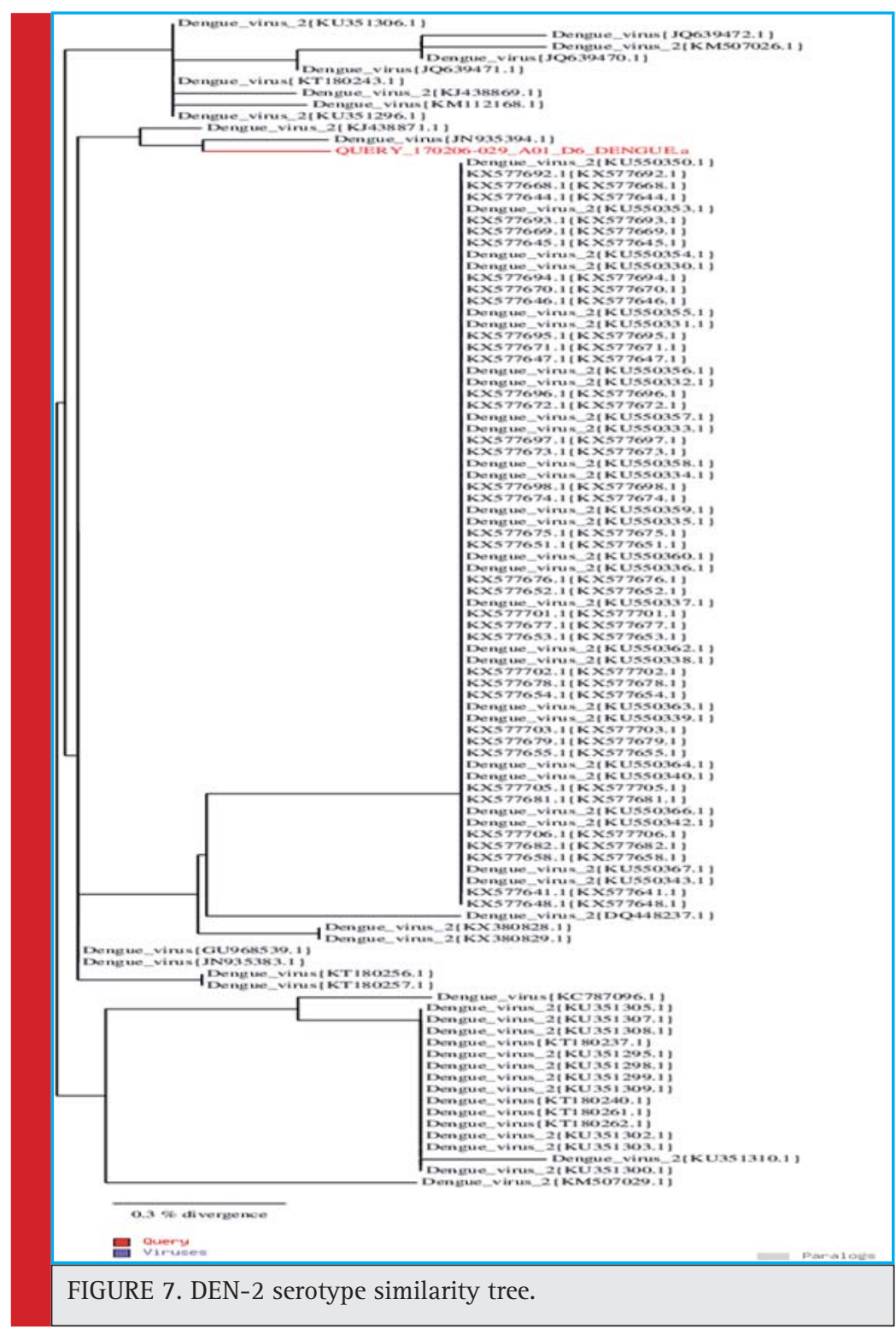

three dengue virus serotypes DEN-1, DEN-2, and DEN-3 are thought to be predominant in the Middle East, especially in Yemen and Saudi Arabia (Nedjadi et al., 2015).

Dengue viruses circulating locally in Saudi Arabia are likely to have been imported into Saudi Arabia by Saudi traveling abroad to dengue endemic countries, or during Hajj and Umrrah seasons, or by migrant labour (Zaki et al., 2008).The introduction of the three dengue virus types in Jazan region may be resulted from several factors; traveling of the Jazan citizens for Hajj and Umrrah or for trade or other purposes, or by traveling abroad to dengue endemic countries, or by migrant labour, or due to the proximity of Jazan region to Yemen where the disease is endemic and the three dengue virus serotypes DEN-1, DEN-2, and DEN-3 are circulating.
The close similarity of DEN-1 in this study to some Asian (Taiwan, Thailand, Vietnam, and Cambodia) and African (Djibouti and Eritrea) types, the similarity of DEN-2 to varies Indian types, in addition to, the similarity of DEN-3 to some Asian types including India, China, and Singapore suggested the likelihood of introduction of theses serotypes to Jazan region either by travelling from and to those countries especially the migrant labours (DEN-1,DEN-2, DEN3,), or through direct introduction from Jeddah (DEN-1 Jeddah genotype) and Yemen which is closet to Djibouti and Eritrea (DEN-1 African origin).

It is stated that shifts in circulating dengue virus type or introduction of new dengue virus type in endemic areas have shown to be related with incidence of severe 


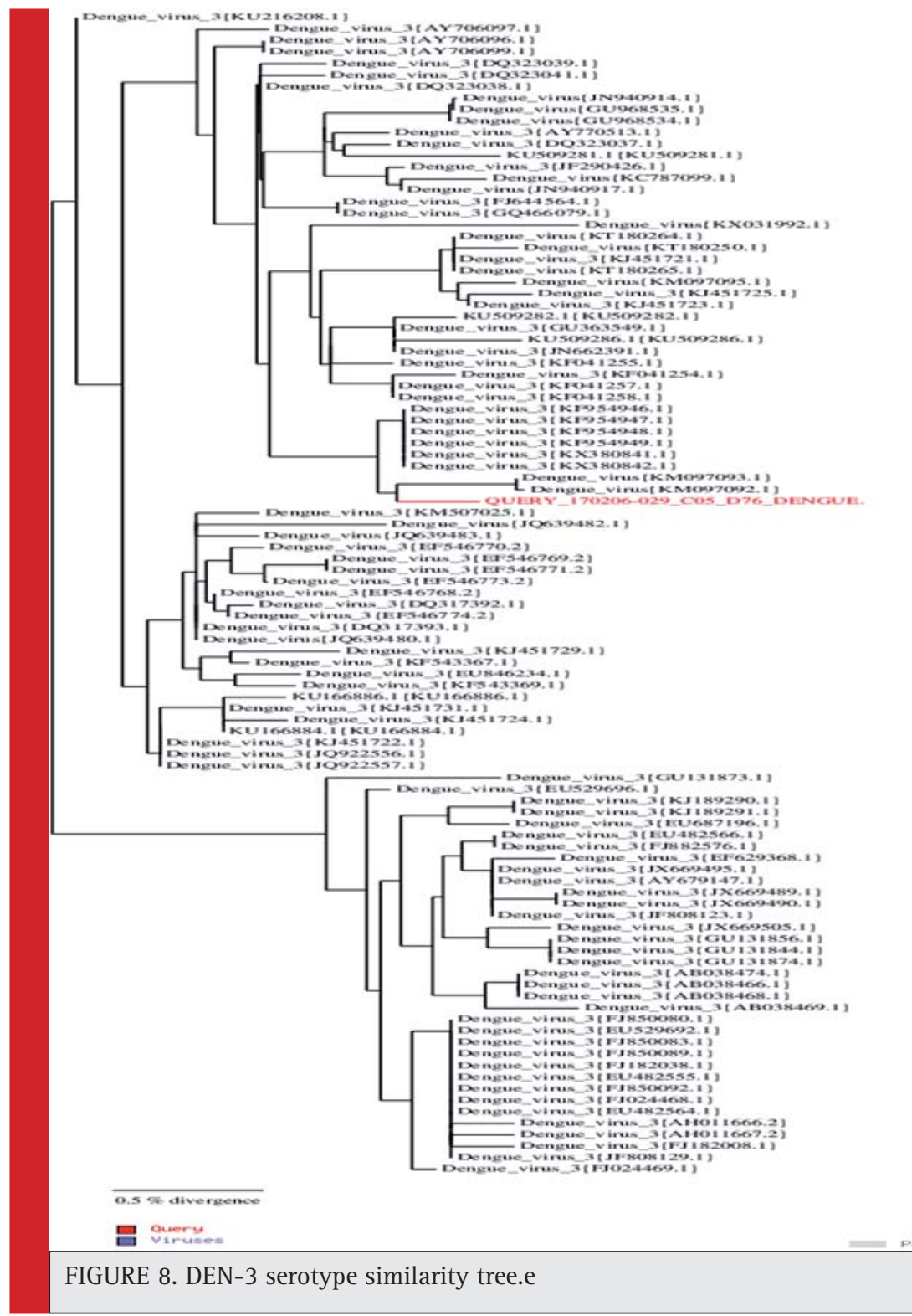

dengue infections; DHF and DSS (Messer et al., 2003; Rico-Hesse et al., 1997). Moreover, it is worthy to note that the primary infections by DEN- 1 and DEN-3 are related with more dengue sever infections, whereas infections with DEN-2 and DEN-4 are associated with increased dengue severity when they present as secondary infections (Balmaseda et al, 2006). Results of our study have analysed multiple dengue serotypes which would help in providing clear evidence of current active dengue transmission and endemicity in Jazan region.

\section{CONCLUSION}

The results of this study reported for the first time the dengue virus types DEN-1, DEN-2, and DEN-3 circu- lating in Jazan region with the DEN-2 being the predominant one. The high seroprevalence of dengue virus infection in Jazan region indicates its endemicity. The present study highlights the importance of tracking the spread of dengue virus types and its implication for analyzing changes in dengue endemicity in specified areas over time. Continuous surveillance of dengue virus serotypes in the region to detect as earlier the local origin circulating serotypes from the imported ones especially new types DEN-4 and DEN-5, for which continued surveillance is imperative. Complete genome sequencing is required for the three detected dengue virus serotypes circulating in the region (DEN-1, DEN-2, and DEN-3) to serve as references for any future epidemiological researches and outbreaks. 


\section{REFERENCES}

Ahmed MM. (2010): Clinical profile of dengue fever infection in King Abdul Aziz University Hospital Saudi Arabia. J Infect Dev Ctries. 4:503-10.

Alsheikh, A.A. (2011): Larval Habitat, Ecology, Seasonal Abundance and Vectorial Role in Malaria Transmission of Anopheles Arabiensis in Jazan Region of Saudi Arabia. Journal of Egyptian society of parasitology, Vol.41. No. 3. December 2001.

Al-Azraqi, T.A., El Mekki, A.A. and Mahfouz, A.A., (2013): Seroprevalence of dengue virus infection in Aseer and Jizan regions, Southwestern Saudi Arabia. Transactions of the Royal Society of Tropical Medicine and Hygiene, p.trt022.

Atschul SF, Madden TL, Schaffer AA (1997): Gapped BLAST and PSI-BLAST. A new generation of protein database search programs. Nucleic Acid Res,25 : 3389-3402.

Ayyub M, Khazindar AM, Lubbad EH, Barlas S, Alfi AY, AlUkayli S. (2006): Characteristics of dengue fever in a large public hospital, Jeddah, Saudi Arabia. J Ayub Med Coll Abbottabad. 18:9-13.

Azhar, E.I., Hashem, A.M., El-Kafrawy, S.A., Abol-Ela, S., Abd-Alla, A.M., Sohrab, S.S., Farraj, S.A., Othman, N.A., BenHelaby, H.G., Ashshi, A. and Madani, T.A., (2015): Complete genome sequencing and phylogenetic analysis of dengue type 1 virus isolated from Jeddah, Saudi Arabia. Virology journal, 12(1), p.1.

Balmaseda A, Hammond SN, Perez L, Tellez Y, Saborio SI, Mercado JC ( 2006) Serotype-specific differences in clinical manifestations of dengue. Am J Trop Med Hyg. 74:449-56.

Banu S, Hu W, Hurst C, Tong S. (2011)Dengue transmission in the Asia-Pacific region: impact of climate change and socioenvironmental factors. Tropical Medicine \& International Health 16: 598-607. doi: 10.1111/j.1365-3156.2011.02734.

CDC (2016): Dengue fact sheet. Available at: https://www.cdc. gov/dengue/ (Accessed 10/03/2017).

Chaturvedi, U. (2006): Dengue and dengue haemorrhagic fever: implications of host genetics. FEMS Immunol. Med. Microbiol. 47, 155-166

Crowell G, Cazelles B, Broutin H, Munayco CV. (2011): The influence of geographic and climate factors on the timing of dengue epidemics in Peru, 1994-2008. BMC Infectious Diseases 11: 164. doi: 10.1186/1471-2334-11-164.

El-Badry AA, El-Beshbishy HA, Al-Ali KH, Al-Hejin AM, ElSayed WSM. (2013): Molecular and seroprevalence of imported dengue virus infection in Al-Madinah, Saudi Arabia. Comp Clin Pathol. doi.org/10.1007/s00580- 013-1704-X.

El-Kafrawy SA, Sohrab SS, Ela SA, Abd-Alla AM, Alhabbab R, Farraj SA, Othman NA, Hassan AM, Bergoin M, Klitting R. (2016): Multiple Introductions of Dengue 2 Virus Strains into Saudi Arabia from 1992 to 2014. Vector Borne Zoonotic Dis. 16(6):391-9. Epub 2016 May 2.

Gibbons, R.V. and Vaughn, D.W. (2002): Dengue: an escalating problem. BMJ 324, 1563-1566
Gmail, M.A., Eisa, Z.M., Eifan, S.A. and Al-Sum, B.A. (2014). Prevalence of dengue fever in Jizan area, Saudi Arabia. Journal of Pure and Applied Microbiology, 8(1), pp.225-31.

Glenn L. Sia Su. (2008): Correlation of Climatic Factors and Dengue Incidence in Metro Manila, Philippines. AMBIO: A Journal of the Human Environment: June 2008, Vol. 37, No. 4, pp. 292-294.

Green, S. and Rothman, A. (2006_: Immunopathological mechanisms in dengue and dengue hemorrhagic fever. Curr. Opin. Infect. Dis. 19, 429- 436 .

Guilarde, A.0.,Turchi MD, Siqueira JB Jr, Feres VC, Rocha B, Levi JE (2008): Dengue and dengue hemorrhagic fever among adults: clinical outcomes related to viremia, serotypes, and antibody response. J. Infect. Dis. 197, 817-824.

Fakeeh M, Zaki AM. (2001): Virologic and serologic surveillance for dengue fever in Jeddah, Saudi Arabia, 1994-1999. Am J Trop Med Hyg 65:764-

Fakeeh M, Zaki AM. (2003): Dengue in Jeddah Saudi Arabia. Dengue Bull 27:13-8.

Khan NA, Azhar EI, El-Fiky S, Madani HH, Abuljadial MA, Ashshi AM. ( 2008): Clinical profile and outcome of hospitalized patients during first outbreak of dengue in Makkah, Saudi Arabia. Acta Trop. 2008;105:39-44.

Konongoi, L., Ofula, V., Nyunja, A., Owaka, S., Koka, H., Makio, A., Sang, R. (2016): Detection of dengue virus serotypes 1, 2 and 3 in selected regions of Kenya: 2011-2014. Virology Journal, 13, 182. http://doi.org/10.1186/s12985-016-0641-0.

Lanciotti, R. S., C. H. Calisher, D. J. Gubler, G. J. Chang, and A. V. Vorndam. (1992): Rapid detection and typing of dengue viruses from clinical samples by using reverse transcriptasepolymerase chain reaction. J. Clin. Microbiol. 30:545551.

Mackenzie JS, Gubler DJ, Petersen LR. (2004): Emerging flaviviruses: the spread and resurgence of Japanese encephalitis, West Nile and dengue viruses. Nature Medicine 10: S98-109. doi: $10.1038 / \mathrm{nm} 1144$.

Madani TA, Abuelzein e-TM, Al-Bar HM, Azhar EI, Kao M, Alshoeb HO, ( 2013): Outbreak of viral hemorrhagic fever caused by dengue virus type 3 in Al-Mukalla, Yemen. BMC Infect Dis. 13:136.

Messer WB, Gubler DJ, Harris E, Sivananthan K, de Silva AM. (2003): Emergence and global spread of a dengue serotype 3, subtype III virus. Emerg Infect Dis. 9:800-9.

Messina JP, Brady OJ, Scott TW, Zou C, Pigott DM, Duda KA, Bhatt S, Katzelnick L, Howes RE, Battle KE, Simmons CP, Hay SI. (2014): Global spread of dengue virus types: mapping the 70-year history. Trends in Microbiology. 2014 March; 22(3):138-146. doi:10.1016/j.tim.2013.12.011.

Ministry of Health. (2007): Ministry of Health Report 2006. Riyadh: Saudi Arabia; ISSN: 1319-3229.

Ministry of Health; Department of Statistics, (2016): Health Statistical Year Book 2016, Saudi Ministry of Health, Riyadh, Saudi Arabia. 
Murray NE, Quam MB, Wilder-Smith A. (2013): Epidemiology of dengue: past, present and future prospects. Clin Epidemiol.; 5:299-309.

Mustafa MS, Rasotgi V, Jain S, Gupta V. (2015): Discovery of fifth serotype of dengue virus (DENV-5): A new public health dilemma in dengue control. Med J Armed Forces India. 71(1):6770. doi: 10.1016/j.mjafi.2014.09.011. Epub 2014 Nov 24.

Nedjadi T., S. El-Kafrawy, S. S. Sohrab, P. Despr'es, G. Damanhouri, and E. Azhar (2015): Tackling dengue fever: current status and challenges,Virology Journal, vol. 12, 2015.

Organji Sameer R., Hussein H. Abulreesh, and Gamal E. H. Osman (2017): Circulation of Dengue Virus Serotypes in the City of Makkah, Saudi Arabia, as Determined by Reverse Transcription Polymerase Chain Reaction. Canadian Journal of Infectious Diseases and Medical Microbiology Volume 2017 (2017), Article ID 1646701, 5 pages. https://doi.org/10.1155/2017/1646701
Rico-Hesse R, Harrison LM, Salas RA, Tovar D, Nisalak A, Ramos C. (1997): Origins of dengue type 2 viruses associated with increased pathogenicity in the Americas. Virology. 230:244-51.

Rico-Hesse R. (2003) Microevolution and virulence of dengue viruses. Adv. Virus Res. 59, 315-341.

Vaughn, D.W. (2000): Dengue viremia titer, antibody response pattern, and virus serotype correlate with disease severity. J. Infect. Dis. 181, 2-9

World Health Organization (1997): Dengue haemorrhagic fever: diagnosis, treatment, prevention and control. 2nd ed. Geneva: WHO: 48-59.

Zaki A, Perera D, Jahan SS, Cardosa MJ. (2008): Phylogeny of dengue viruses circulating in Jeddah, Saudi Arabia: 1994 to 2006. Trop Med Int Health. 13:584-92. 